us any, give us thyself some of the bread of health, for he must at the same time watch over the sacrifices; the bread of health is due us with the portion which reverts to us.

The purpose of this dramatic sketch was apparently as a contemporary satire on a religion whose observances had become empty forms, and on its feminine devotees whose interests were chiefly in the artistic treasures of the temple and, like the temple guardian, in the reversion which they were to receive from their own sacrifice. Therocritus, the master and older contemporary of Herondas, has a very similar passage in his "Syracusans," in which Praxinoas scolds her servant, and with Gorgo, at the temple of Adonis, goes into ecstasies of admiration over the objects of art, bijouterie et vertu, which are heaped up there. The same motive may be found also among certain plays of the earlier dramatists, notably in Sophron's "Women at the Isthmian Games," and in the @eapoi of Epicharmes, where visitors to the temple at Delphi are overcome with wonder at the wealth and splendor of the temple treasure and decorations.

Perhaps the parallel is not altogether lacking in our own day, when patients are sometimes more eager to obtain the bread of health than to pay the adequate sacrifice and oblation demanded in return. Be that as it may, the vivid lines of Herondas serve not only to recreate for us the forms and scene of that old pagan worship of Asklepios, but to portray something of the unchanging human nature which we see today in hospital and office as it was then in the temple of our tutelar deity.

\section{THE TREATMENT OF HYPOSPADIAS.}

BY HOWARD A. LOTHROP, A.M., M.D., BOSTQN,

Assistant Professor of Surgery, Harvard Medical School; Visiting

Hypospadias is a congenital defect whereby a part of the floor of the urethra is deficient. This deficiency begins at the glans and, according to its extent, the cases are divided into three groups: (1) the glandular type, (2) the penile type, and (3) the scrotal type.

The glandular type is one in which the deficiency is opposite the glans penis. This is very common and is generally left untreated because no function is interfered with.

In the penile type a part of all the floor of the penile urethra may be wanting and the functional disturbance varies according to the location of the meatus. The nearer the meatus to the penoscrotal angle, the greater the disturbance of function, such as poor control of the stream during micturition, obstruction with dilatation of the urethra from a small meatus, and finally, in the severer cases, some penile deformity, which is due to a longitudinal band underneath the penis.
In the scrotal type, which, fortunately, is rare, the deformity is great and the functional disturbance serious. The penis is greatly curved and the glans is firmly held by the fibrous band to the region of the scrotum, so that coitus is impossible and the location of the meatus is such that the parts are irritated from frequent wetting with urine.

TREATMENT.

In that the glandular type causes no particular inconvenience or functional disturbance, restoration of the urethra is not often attempted, both because there is no pressing indication and because it is difficult to establish a canal through the glans penis. The scrotal type is so rare and its attempted relief is attended with so many difficulties, contra-indications and failures that it will not be considered further here.

There are various plastic operations for the treatment of the penile type of hypospadias. In several cases operated upon by the writer, the best results have been obtained by using a flap operation described by Thiersch in 1869 for the treatment of epispadias and adapted later by Anger for cases of hypospadias. This technic, modified slightly according to the exigencies of each case, has been used and satisfactory results obtained. More than ordinary care is required in the various steps of the operation. Instruments should be small and the flaps handled with delicate hooks and forceps so as to avoid unnecessary injury. Hemorrhage is not troublesome.

\section{TO STRAIGHTEN THE PENIS.}

This is accomplished by making one or two transverse incisions through the tissue below and between the corpora cavernosa, generally extending somewhat deeply into the latter. The penis is then extended so as to open the wounds and the opposite ends of the incisions are approximated and thus these wounds are closed longitudinally. Hemorrhage is easily controlled by sutures; preferably of fine silkworm gut or silver wire. Examination will determine whether the straightening operation will be necessary and about six months should elapse after this step before making a urethra, in order to allow for all contraction and to establish good circulation for the flaps which are to be made later.

THE FORMATION OF THE URETHRA.

Incisions are made so as to form two flaps, $A$ and B, (Fig. 1), the former to be reflected over a catheter and the latter to be stretched over all the denuded area. A traction stitch may be passed through the glans and the penis held retracted on the abdomen. Flap A is made with its base 1-4 at the line of the urethra and should be about three-fourths of an inch wide. The incision 1-2 should include some of the tis- 


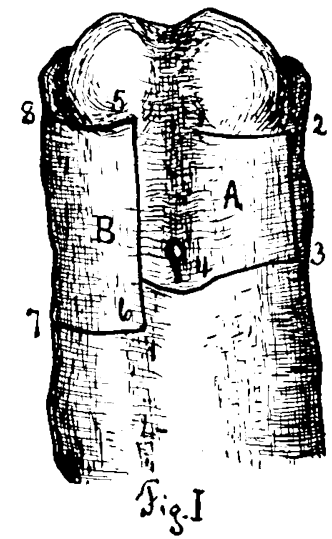

sue of the glans so as to make the new meatus reasonably near the end of the penis. The incision 3-4 should be carried proximal to the meatus and then across to meet incision 5-6. The flap should be as thick as the tissues will allow and should be dissected to the base line 1-4. The flap $B$ is then formed by making incision 5-6 which is carried about one-half an inch proximal to the original meatus. The incisions 5-8 and 6-7 are carried around toward the dorsum of the penis so as to allow the formation of a flap which, eventually, can be stretched to incision 2-3. Occasionally the meatus will have to be enlarged, as was necessary in the case of a child of eight years (Fig. 1), because the opening was so small as to act as a stricture. Hence, a short ventral incision was made. Next, a small rubber catheter is inserted into the bladder, which is to remain seven to fourteen days according to circumstances, although it may have to be changed for one reason or another. In one case where the deficiency involved only a small portion of the penile urethra, a short tube included only the distal two inches of the

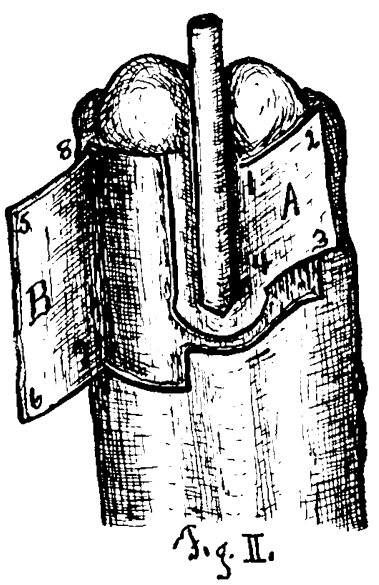

penis and was easily retained by a stitch through the glans (Fig. 3). One subsequent minor operation was required to close a small fistula which persisted in the vicinity of the original meatus and finally a catheter had to be inserted into the bladder so as to keep the field of opera- tion dry. Care is needed to retain the catheter. The urine is conducted through a tube to a bottle by the bedside. A little skin should be trimmed off the proximal edge $3-46-7$ so as to make an even border. The stitches are next applied. Three or four mattress sutures of fine silkworm gut, fine wire, or horsehair, according to circumstances, are placed in such a way (Fig. 3) as to draw flap B towards the under side of the penis and also retain flap $\mathrm{A}$ folded over the catheter with its free border 2-3 in contact with incision 5-6 as illustrated. There will be no undue tension of the flaps if cut suffi-

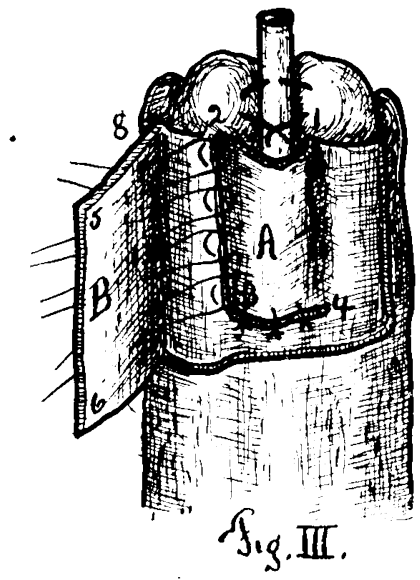

ciently large. The skin around the proximaI side of the meatus should be freed near the base of flap A (Fig. 2) and sutured to the reflected border 3.4 (Fig. 3). Finally, flap B is drawn across the wound and its borders sutured on three sides. Thus the flap B covers the line 3-4, so that 3-4 and 6-7 are not opposite each other. If the incision 1-2 is made in the substance of the glans and 5-8 is correspondingly distal, the new meatus will be sufficiently near the end of the penis. The operations devised for restoring
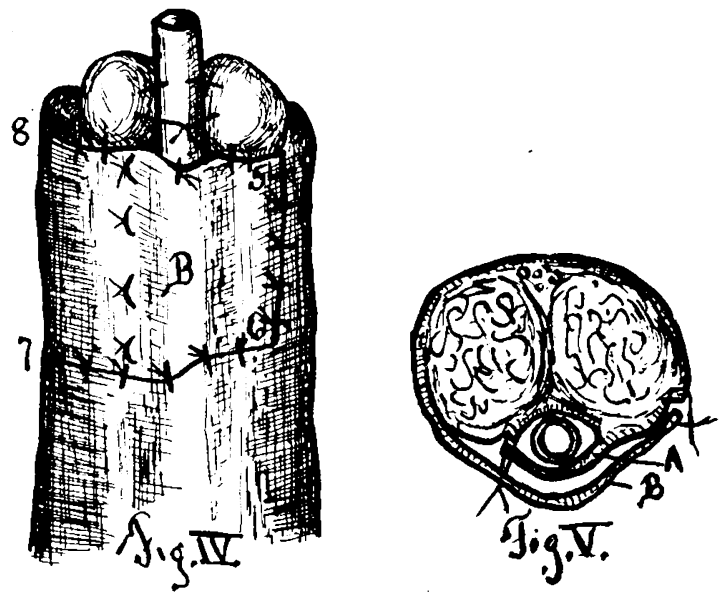

the urethra through the glans penis are not very satisfactory and, if successful, a stricture is apt to develop. When the operation is completed the parts are protected by a sterile gauze dressing. A moderate amount of edema is to be ex- 
pected but this subsides soon. The drying of the mucous membrane and the crusts which may obstruct at the new meatus are prevented by the application of boric acid ointment. Careful attention must be paid to the wound during the convalescence and the catheter must be kept in perfect order. The latter is borne even by small children without discomfort or risk of urinary infection and should be retained until the wound is healed.

\section{Uliniral B⿴囗十partmunt.}

\section{A CASE OF PELlagRa.*}

BY WAKREN H. SHERMAN, M.D., GRANITEVILLE, MASS.

The patient is a man 68 years old. He was born in England and came to this country 26 years ago. With the exception of four visits to his former home, he has always lived in Massachusetts. He has not been out of this state for nine years, and has never been farther south than New York. His occupation while in England was that of a farmer, but since he came to America he has always worked in a woolen mill, except for a short time 20 years ago when he worked as a farm hand. He has been a moderate user of tobacco and alcohol. The family history is negative. His wife is dead. There are five children, all living. $\mathrm{He}$ has always been healthy with the exception of several attacks of indigestion at intervals of from one to three years. Some time last March or April he began to have slight epigastric discomfort after eating, and to get tired easily. I was called on July 30 , when he complained of constant pain in the epigastric and right hypochondriac regions, at times becoming severe. At this time he was constipated, which has alternated with diarrhea throughout the attack. He slept well, but during the day was more irritable than usual. His appetite was poor. About the 10th of August a dark erythema appeared on the back of his left hand, which extended from the wrist to the second joints of the tingers. After three or four days the same thing appeared on the back of the right hand, and on the face, the cheeks first, and gradually extended to chin, forehead, ears, nose and back of the neck.

By the time the eruption had extended thus far, there appeared scaly patches on the cheeks, and a little later on the hands. The scales were of a much darker color, which gave a brownish appearance to the parts affected. Bullae and vesicles appeared on the hands but not on the face. Later nearly all the epidermis exfoliated from the backs of the hands leaving them raw and sore. The backs of the fingers were affected to the tips but not at all on the palmar surface, there being a line of demarcation at the sides, where the fingers came in contact. There was no itching nor pain, the sensation being described as more of a burning feeling. The face did not become sore but did desquamate. He has had very severe stomatitis and salivation; some nausea but no vomiting. The tongue was coated at first but later became red and beefy. At one time he complained of difficulty. in swallowing, and of a burning sensation in the throat and under the sternum. There has been more or less pain in the

* Read at a meeting of the Middlesex North District Medical Society, Nov., 1912. epigastrium throughout his illness but it has not been severe since the eruption appeared.

There were no hallucinations nor delusions, but there was a good deal of mental depression. His memory was somewhat impaired. He seemed dull and was slow in replying to questions. His voice was weak and he had a shuffling gait. The temperature has been normal; the pulse slightly accelerated; urine negative. He denied having eaten maize or any corn products. He has lost considerable weight.

At this time the hands have ceased to desquamate and have entirely healed, the new epidermis being rather darker in color than normal. The patient is feeling better, his voice is stronger and he walks better, but does not care to go out very much, and takes very little interest in affairs. There is some anesthesia of the skin since the eruption has disappeared.

\section{PELLAGRA, WITH A REPORT OF CASES."}

BY ELISHA H. COHOON, M.D., HOW ARD, R. I.

Assistant Physician, State Hospital for the Insane, Howard, R. I. and

FREDERIC J. FARNELL, M.D., HOWARD, R. 1 .

Neuro-serologist, State Hospital for the Insane, Howard, R. I., and Butler Hospital; Neurological Externe, Rhode Island Hospital, Providence, $R$. $I$.

IN his first work on insanity in 1883, Professor Spitzka1 states: "Pellagrous insanity will not be discussed in this volume as it does not occur in America and is limited to such countries as Italy, where maize forms a staple article of diet and where the disease known as pellagra, attributed to living on spoiled maize, occurs in endemic form." In his first edition on Neurology and Psychiatry, Dr. Peterson ${ }^{2}$ said that pellagra occurred eminently in poverty-stricken and desolate districts and was due presumably to the use of diseased and fermenting maize.

It will not be necessary to go further into the history of pellagra. Suffice it to say that this disease was not looked for in this country; that at least its presence as such was not recognized or else that it has been classed with other forms of disease either in reference to the skin, the intestinal tract or the nervous system.

In the United States the first cases of pellagra were reported by Dr. Gray of New York and Dr. Tyler ${ }^{3}$ of Massachusetts in 1864. Nothing more was heard of the disease until 1902 when Dr. Sherwell ${ }^{4}$ of Brooklyn, New York, reported two cases among Italian sailors soon after entering port. In 1907 it was again recognized by Drs. Merrill ${ }^{5}$ and Babcock ${ }^{6}$ of South Carolina and independently, at about the same time, by Dr. Searcy ${ }^{7}$ of Alabama, so that in 1911 there were cases of pellagra diagnosed in the state of South Carolina alone, to the number of 2100 . Notwithstanding, there still appears to be some doubt as to the presence of pellagra in some of the United States as only twenty-seven states have reported the probability of cases.

At the beginning of 1911 the number reported was 7000 , though many writers believe this * Read (in part) before Providence Medical Society, Apr 1, 1912. 